\title{
Choriocarcinoma brain metastasis in a patient in the third trimester: a case report
}

\author{
Chunjuan Shen ${ }^{1}$, Ling $\mathrm{Ai}^{1 *}, \mathrm{Kai}^{\mathrm{Li}}{ }^{2}$, Yunfei Cao ${ }^{1}$, Hanbing $\mathrm{Wu}^{1}$ and Dandan Sun ${ }^{1}$
}

\begin{abstract}
Background: Metastatic choriocarcinoma in the third trimester of pregnancy is extremely rare.

Case presentation: A 25-year-old Chinese woman (gravida 3, para 0) who was 28 weeks pregnant was admitted for sudden convulsion, aconuresis, and unconsciousness. The decision was made to perform an emergency cesarean delivery and craniotomy, hematoma clearance, and decompression. Pathological examination confirmed choriocarcinoma with brain metastasis. The patient underwent chemotherapy with the etoposide, cisplatin (EP) and etoposide, methotrexate and dactinomycin alternating with cyclophosphamide and vincristine (EMACO) regimens. A satisfactory result was achieved.
\end{abstract}

Conclusions: When encountering intracranial mass or bilateral pulmonary nodules in a pregnant woman, especially one in the third trimester, metastatic choriocarcinoma should be considered.

Keywords: Choriocarcinoma, Pregnancy, Metastasis, Chemotherapy, Elective caesarean section

\section{Introduction}

Choriocarcinoma may develop during any form of gestation: abortion or tubal pregnancy, term or preterm gestation, or hydatidiform moles. Clinical follow-up is considered to be essential due to the high risk of metastases. Outside the pelvis, lung metastases are relatively common, occurring in $80 \%$ of cases; brain metastases are relatively uncommon (10\%) [1]. Here we report a rare case of a young pregnant woman (gravida 3, para 0 ) with choriocarcinoma brain metastasis in the 28th gestational week. The aim of this report was to present this rare case and discuss the management of choriocarcinoma with brain metastasis.

\footnotetext{
*Correspondence: ailing20200101@sina.com

${ }^{1}$ Department of Obstetrics and Gynecology, Jiaxing Maternity and Child Health Care Hospital, Jiaxing University Affiliated Maternity and Child Hospital, Jiaxing, Zhejiang, China

Full list of author information is available at the end of the article
}

\section{Case report}

A 25-year-old Chinese woman in her 28th week of pregnancy was admitted to the local hospital with a complaint of severe and unremitting headaches, nausea, and vomiting. The patient was given metoclopramide (dose $10 \mathrm{mg}$ ) by intramuscular injection to alleviate her symptoms, with no effect. She was then transferred to Jiaxing Maternity and Child Health Care Hospital. After admission, she presented sudden convulsion, aconuresis, and unconsciousness. Blood pressure, pulse, and temperature were 90-100/60-70 mmHg, $90-100 \mathrm{bpm}$, and $36.7-37{ }^{\circ} \mathrm{C}$, respectively. The patient was administered intravenous mannitol ( $1 \mathrm{~g} / \mathrm{kg}$ over a 15 -min period).

The patient's medical history revealed that her last pregnancy was terminated by artificial abortion in August 2017. There had also been one previous artificial abortion 3 years earlier. After the last artificial abortion, the patient's menstrual cycle was regular, and there was no irregular uterine bleeding. The patient had no other special family, medical, and surgical history. After leaving college, she worked as a secretary and she was registered original author(s) and the source, provide a link to the Creative Commons licence, and indicate if changes were made. The images or other third party material in this article are included in the article's Creative Commons licence, unless indicated otherwise in a credit line to the material. If material is not included in the article's Creative Commons licence and your intended use is not permitted by statutory regulation or exceeds the permitted use, you will need to obtain permission directly from the copyright holder. To view a copy of this licence, visit http://creativecommons.org/licenses/by/4.0/. The Creative Commons Public Domain Dedication waiver (http://creativeco mmons.org/publicdomain/zero/1.0/) applies to the data made available in this article, unless otherwise stated in a credit line to the data. 
as a resident of Jiaxing Zhejiang. The patient had never smoked or consumed alcohol.

Examination Blood pressure, pulse, and temperature were $90 / 58 \mathrm{mmHg}, 110 \mathrm{bpm}$, and $36.3{ }^{\circ} \mathrm{C}$, respectively. On examination, she had no signs of brain trauma. Meningeal signs were positive, with cervical rigidity. Coma was absent; there was a minimally reactive $6-\mathrm{mm}$ right pupil with pupillary reaction to light and a reactive 5-mm left pupil with a faint pupillary reaction to light. In muscle group I the muscular tension in the limbs was increased. The Glascow Coma Scale score was 5. She had normal heart sounds and normal breath sounds of the lungs. The abdominal examination revealed central obesity and a bulky uterus with a size corresponding to 28 weeks of gestation. No adnexal masses were noted. Computerized tomography (CT) scanning of the brain revealed a hemorrhagic mass in the right occipital region extending into the ventricle system, with herniation of the brain. Uterine ultrasonographic depicted 28-weekold fetus and the absence of any abnormal mass.

Operation A tentative plan was made for an emergency cesarean delivery and craniotomy, hematoma clearance, and decompression (Fig. 1). The fetus was delivered, with Apgar scores at 1.5 min of 2 and 3 and a body weight of $1180 \mathrm{~g}$, and the newborn was admitted to the neonatal intensive care unit. The uterus, pelvis, and abdomen showed no definitive abnormalities. Areas of focal hemorrhage were removed and brain pressure relaxed; all vital signs were within normal limits.

Postoperative The patient recovered consciousness, and the neurological symptoms were relieved at 1 day after the surgery. Re-examination of the CT scan of the brain showed that the right occipital hematoma was essentially removed, and CT scan of the lung showed a mass in the upper lobe of the right lung consisting of irregular, multiple bilateral pulmonary nodules (Fig. 2).

Pathological findings Pathological examination of the brain hemorrhagic mass showed a histological pattern and structure of metastatic choriocarcinoma. Immunohistochemistry was: $\mathrm{CK}(\operatorname{pan})(+), \mathrm{HCG}(+)$, and $\mathrm{HPL}(+)$ (Fig. 3).

Postoperative therapy The patient began chemotherapy at 7 days after the surgery with a regimen of etoposide and cisplatin (EP) in the first two courses of treatment (etoposide $100 \mathrm{mg} / \mathrm{m}^{2}$, cis-platinum $20 \mathrm{mg} / \mathrm{m}^{2}$ ). She received an injection of palonosetron hydrochloride (dose $0.25 \mathrm{mg}$ ) intravenously about $30 \mathrm{~min}$ before each chemotherapy course. The duration of one course was 2 days, and the interval between each course was 1 week. She was started on the EMACO regimen as the third course of treatment (etoposide $100 \mathrm{mg} / \mathrm{m}^{2}$, methotrexate $100 \mathrm{mg} / \mathrm{m}^{2}$ with methotrexate $200 \mathrm{mg} / \mathrm{m}^{2}$ for $12 \mathrm{~h}$, folic acid $15 \mathrm{mg}$ and actinomycin D $0.5 \mathrm{mg}$, alternating with cyclophosphamide $600 \mathrm{mg} / \mathrm{m}^{2}$ and vincristine $1 \mathrm{mg} / \mathrm{m}^{2}$ ). Prior to chemotherapy, her $\beta$-human chorionic gonadotropin ( $\beta$-HCG) level was $12,162.53 \mathrm{U} / \mathrm{L}$; after two courses of therapy the serum $\beta$-HCG level had changed significantly $(66,486.37 \mathrm{U} / \mathrm{L})$; and after the third course, $\beta$-HCG level had dropped by more than tenfold. The patient's general condition was not poor. Laboratory tests showed that the leukocyte level had fallen to $2.7-3.2 \times 10^{9} / \mathrm{L}$, but all other results (liver and renal functions, urinalysis, serology, microbiology) were about normal. The patient was administered recombinant human granulocyte-colony stimulating factor by hypodermic injection to promote the leukocyte level, resulting in to $8-15 \times 10^{9} / \mathrm{L}$. After eight cycles of chemotherapy, the $\beta$-HCG level had returned to normal $(3.68 \mathrm{U} / \mathrm{L})$ (Fig. 4). The patient was administered ten cycles chemotherapy and was fortunately able to tolerate full-dose chemotherapy.

Follow-up After eight weeks, the newborn baby was discharged in good condition, and she is developmentally normal with no cognitive or motor delays. The patient remains disease free based on the $\beta$-HCG level and radiology examination for 1 year. The $\beta$-HCG level and the results on the $\mathrm{CT}$ scans of the brain and lung are within the normal range.

\section{Discussion}

Metastatic choriocarcinoma in a patient at a late stage of pregnancy is extremely rare. It is more likely to be associated with hydatidiform moles, and even then only $2-3 \%$ of hydatidiform moles progress to choriocarcinoma [1]. Our patient presented with severe and unremitting headaches, nausea, and vomiting, all typical systems of choriocarcinoma. The $\mathrm{CT}$ scans of the brain and lungs were highly suspicious of pulmonary tuberculosis metastasis; however, the preliminary diagnosis was a misdiagnosis. Fortunately, sequential management of the patient was not delayed. We observed a significant rise in the level of $\beta$-HCG. A background search of the patient's menstrual and obstetrical history revealed that the last artificial abortion was mild trophoblastic hyperplasia. The patient did not have a follow-up examination of HCG level. It was considered that trophoblastic hyperplasia evolved into choriocarcinoma in the current pregnancy. Pathological examination of the brain hemorrhagic mass supported the diagnosis of choriocarcinoma. 


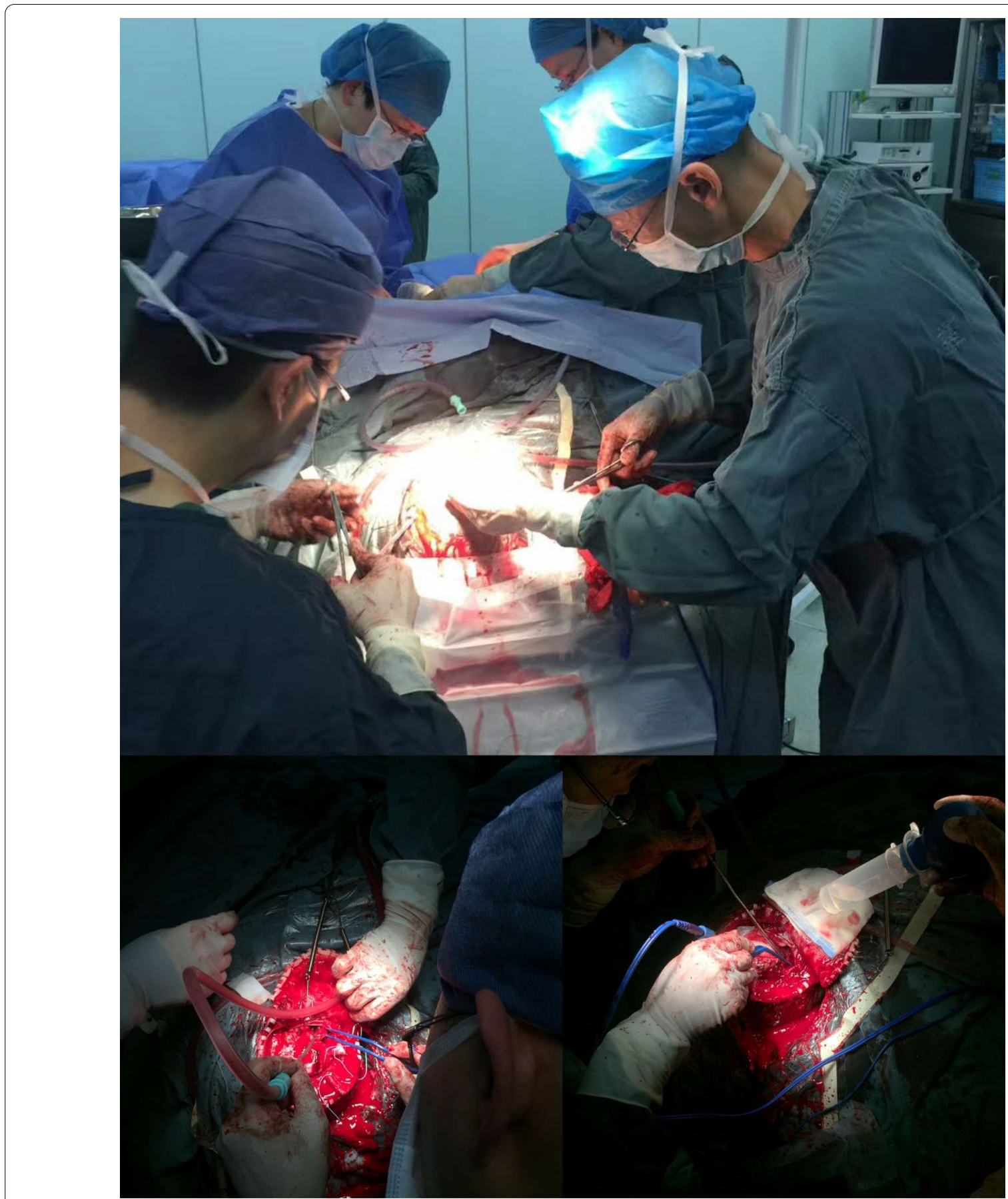

Fig. 1 Intraoperative picture

Yang et al. [2] reported a case of gestational choriocarcinoma misdiagnosed as pulmonary tuberculosis in a patient who had no abnormal uterine bleeding. When a patient presents with multiple pulmonary nodules, brain multiple mass, or other viscera multiple mass, we must consider choriocarcinoma, whether the patient is pregnant or not, whether or not menstruation has ceased, and whether or not there is irregular vaginal bleeding. The doctor should take note of serum $\beta$-HCG levels and obstetrical history.

Mamelak et al. reported a case of choriocarcinoma brain metastasis in a patient in her 30th week of 


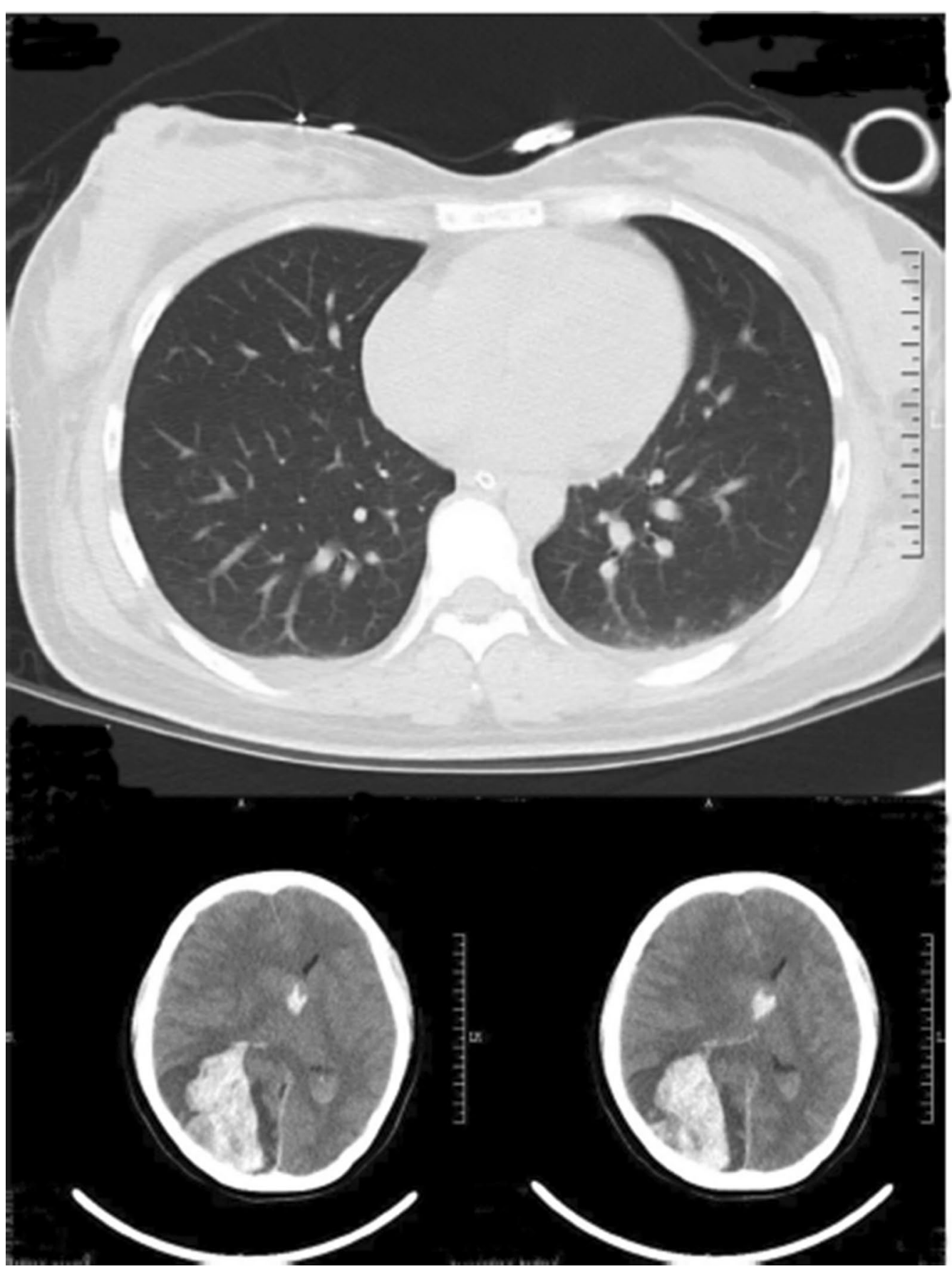

Fig. 2 Computerized tomography scann of the lung and brain

pregnancy [3]. The patient was treated with surgical removal of the brain metastasis and a cesarean section. We also performed caesarean section and craniotomy, hematoma clearance, and decompression simultaneously in our patient, and surgically removed a significant mass of brain metastasis. It was noted in our patient that when the brain mass grows progressively, neurological symptoms deteriorate promptly.

Chemotherapy offersa cure to $80 \%$ of choriocarcinoma metastases, even those to the lung, brain, or other any body part [4]. One case report showed that a patient with metastatic choriocarcinoma treated with EMACO 


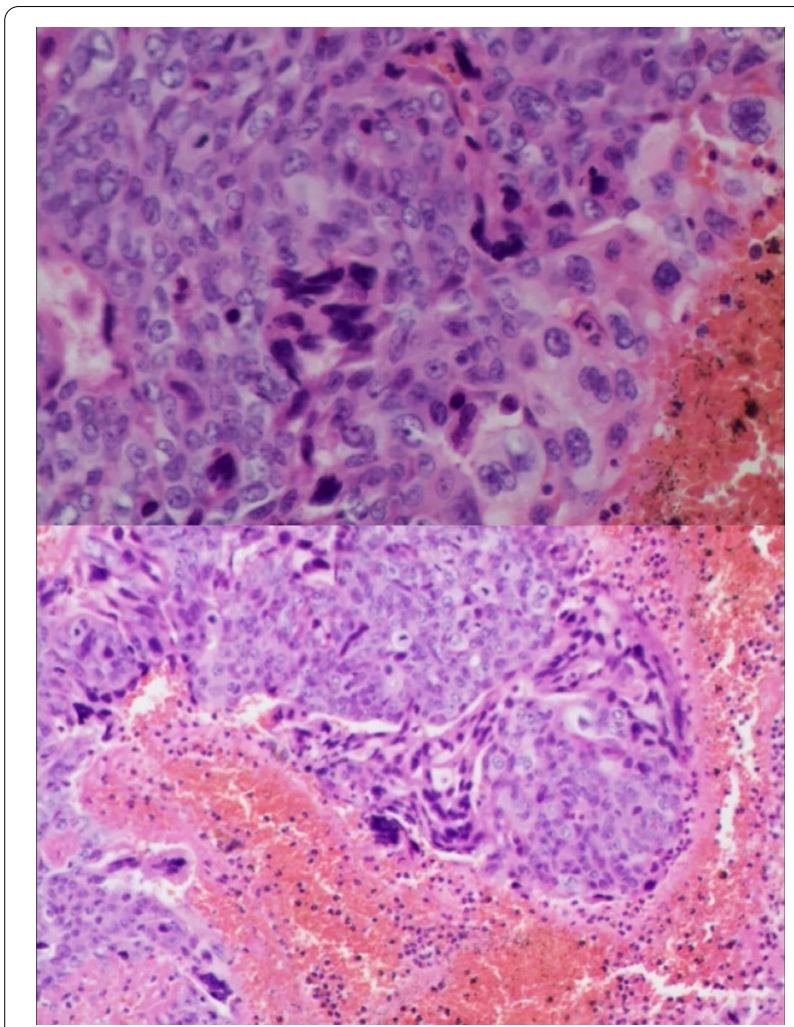

Fig. 3 Pathological examination of the brain hemorrhagic mass

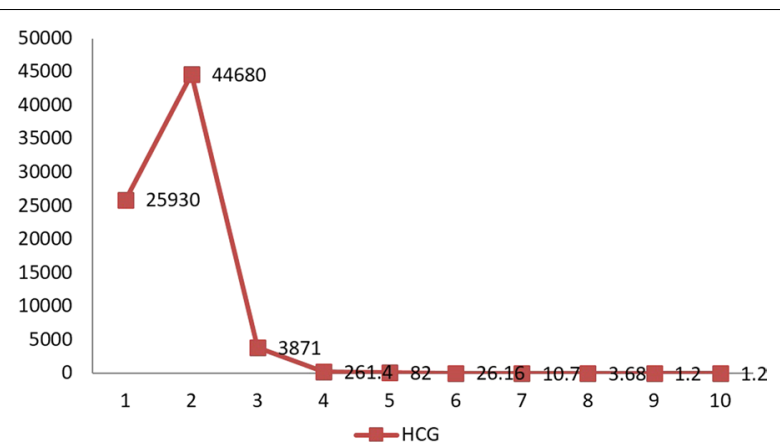

Fig. 4 The level of serum beta-human chorionic gonadotropin (HCG) after chemotherapy.

chemotherapy achieved satisfactory clinical prognosis [5]. Yu et al. reported a case of patient with metastatic choriocarcinoma who required combination chemotherapy as EP/EMA (toposide, methotrexate, and dactinomycin) [6]. Mamelak et al. reported a case of brain metastatic choriocarcinoma that was treated with brain radiotherapy and chemotherapy within 1 week after surgery [3]. Brain metastatic choriocarcinoma requires multidrug combined therapy, including craniotomy, whole brain radiotherapy, and EP-EMA or EMA-CO chemotherapy [7]. However, the effectiveness of radiotherapy is still debatable. In our case, the patient was very satisfied with her recovery on the EP and EMACO regimens.

We searched PUBMED and Web of Knowledge for studies on intrauterine pregnancy associated with brain metastatic choriocarcinoma. We found that choriocarcinoma brain metastasis presented between 28 and 32 weeks of pregnancy $[3,6,8,9]$. Lorna et al. [8] reported a case of metastatic choriocarcinoma in which the initial $\mathrm{CT}$ of the brain was negative for any lesions in the 20th week of intrauterine pregnancy. The patient developed intracranial metastases after the induction of labor at 32 weeks of gestation. The time to development of brain metastasis was unknown.

\section{Conclusions}

Gestational choriocarcinoma in a third trimester pregnancy is rare, but metastatic lesions are numerous. If an intracranial mass or bilateral pulmonary nodules are found in a pregnant woman, especially during the third trimester, metastatic choriocarcinoma should be considered.

\section{Abbreviations}

CT: Computerized tomography; EMA: Etoposide, methotrexate, and dactinomycin; EMACO: Etoposide, methotrexate, and dactinomycin alternating with cyclophosphamide and vincristine; EP: Etoposide, cisplatin; $\beta$-HCG: $\beta$-Human chorionic gonadotropin; SCl: Web of Knowledge.

\section{Acknowledgements}

Not applicable.

\section{Authors' contributions}

CS has made substantial contributions to the conception and design of the work and drafted the work. LA has drafted the work or substantively revised it. $\mathrm{KL}$ has made substantial contributions to the acquisition, YC to analysis, HW to interpretation of data, DS to the creation of new software used in the work. All authors read and approved the final manuscript.

\section{Funding}

None.

\section{Availability of data and materials}

We make readily reproducible materials described in the manuscript.

\section{Declarations}

Ethics approval and consent to participate

Not applicable.

\section{Consent for publication}

Written informed consent was obtained from the patient for publication of this case report and any accompanying images. A copy of the written consent is available for review by the Editor-in-Chief of this journal.

\section{Competing interests}

The authors declare that they have no competing interests.

\section{Author details}

${ }^{1}$ Department of Obstetrics and Gynecology, Jiaxing Maternity and Child Health Care Hospital, Jiaxing University Affiliated Maternity and Child Hospital, 
Jiaxing, Zhejiang, China. ${ }^{2}$ Department of Orthopedics, The Second Hospital of Jiaxing, Jiaxing, Zhejiang, China.

Received: 24 September 2020 Accepted: 22 March 2021

Published online: 29 July 2021

\section{References}

1. Lurain JR. Gestational trophoblastic disease I: epidemiology, pathology, clinical. Am J Obstet Gynecol. 2010;203:531-9.

2. Yang L, Xu P, Xi M, et al. FIGO stage IV gestational choriocarcinoma misdiagnosed as pulmonary tuberculosis. Oncol Lett. 2015;10:1924-6.

3. Mamelak AN, Withers GJ, Wang X. Choriocarcinoma brain metastasis in a patient with viable intrauterine pregnancy. J Neurosurg. 2002;97:477-81.

4. Seckl MJ, Sebire NJ, Fisher RA, et al. Gestational trophoblastic disease: ESMO Clinical Practice Guidelines for diagnosis, treatment and follow-up. Ann Oncol. 2013:24:39-50.
5. Schmid P, Nagai $Y$, Agarwal R, et al. Prognostic markers and long-term outcome of placental-site trophoblastic tumours. Lancet. 2009;374:48-55.

6. Yu P, Diao W, Jiang X. A successfully treated metastatic choriocarcinoma coexistent with pregnancy: a. Medicine. 2016;95:3505.

7. Piura E, Piura B. Brain metastases from gestational trophoblastic neoplasia: review of pertinent literature. Eur J Gynaecol Oncol. 2014;35:359-67.

8. Brudie LA, Ahmad S, Radi MJ, et al. Metastatic choriocarcinoma in a viable intrauterine pregnancy treated with EMA-CO in the third trimester: a case report. J Reprod Med. 2011;56:359-63.

9. Zhu Y, Cheng N, Liu J. Third-trimester intrauterine pregnancy complicated by metastatic choriocarcinoma. Int J Gynaecol Obstet. 2013;122:84-5.

\section{Publisher's Note}

Springer Nature remains neutral with regard to jurisdictional claims in published maps and institutional affiliations.
Ready to submit your research? Choose BMC and benefit from:

- fast, convenient online submission

- thorough peer review by experienced researchers in your field

- rapid publication on acceptance

- support for research data, including large and complex data types

- gold Open Access which fosters wider collaboration and increased citations

- maximum visibility for your research: over $100 \mathrm{M}$ website views per year

At BMC, research is always in progress.

Learn more biomedcentral.com/submissions 